\title{
A Study on Formative Style of Silla Bell
}

\author{
Jaehyuck Lee $^{\dagger}$, Kim Cheeyong ${ }^{\dagger+}$
}

\begin{abstract}
Maintaining our tradition makes us have pride for our nation and plays important role for recognition and establishment of identity for our unique culture in the world. Contrast to the western scientific technique, the scientific technique of Silla Bell absorbed in the life of our nation is the fruit of wisdom science found through rich life and experience by harmony between our nation and nature.

Today, ideological backgrounds for many cultural heritages weren't be found and there are many overflowing hypothesis. Silla Bell is the plastic art including cumulative utopia of the racial spirit. So there would be the information of the racial spirit including symbolization, artistry, creativity, and historicity. However, unlikely with the words, it is the profoundly concentrated shape, so the meaning can be diluted or distorted in later generation. The efforts to figure out the symbolization in Korean bells, especially Silla bell according to its exclusive shape, but no hypothesis was accepted as an established theory of academia by gaining extensive agreements.

Thus this paper traces the symbolic meaning accumulated in the shape and prepares for the theoretical background accessing to the artistic spirit of forebears who created super-humanity formativeness. Also regarding the Silla bell which is regarded as the best Buddhist metal craft that people believe they can be free from the anguish at the time of listening to its sound, we studied the symbolization of the bell as the religious ritual custom as well as the possibility to utilize the bell as a motif of living art in the aspect of formative expression.
\end{abstract}

Key words: Temple Bell, Korea Bell, Silla Bell, Formative Beauty

\section{INTRODUCTION}

\subsection{Purpose of study}

Maintaining our tradition plays an important role for recognition and establishment of identity for the root of our culture. Contrast to the western scientific technique, the scientific technique of Silla Bell absorbed in the life of our nation is the fruit of wisdom science found through rich life and experience by harmony between our nation and nature.

In order to understand specific culture of a na-

※ Corresponding Author: Kim Cheeyong, Address: (614-714) 부산광역시 진구 엄광로 176 동의대학교 영상정 보공학과, TEL : +82-10-4584-4036, FAX : +82-51-8902265, E-mail:kimchee@deu.ac.kr

Receipt date: Sep. 8, 2013, Revision date: Sep. 24, 2013 Approval date: Sep. 27, 2013

${ }^{+}$Department of Formative Design, Kyunghee University (E-mail: ohholee@hanmail.net)

${ }^{+\dagger}$ Dept. of Visual Information Engineering, Dong-Eui University tion, letters, pattern, and plastic arts are the criterion. Especially plastic arts make creativity of culture and art possible to be understood with harmony of various shapes and colors. While the letters and patterns are functioned as the meaning of direct expression of opinion, plastic arts have the function as an indirect creation which has cumulative technique and artistic spirit and is profound medium transmitting even historical hegemony over time and space. For the plastic arts with $\mathrm{cu}^{-}$ mulative utopia of the racial spirit, the information including symbolization, artistry, creativity, and historicity is permeated in there. However, unlikely with the words, it is the profoundly concentrated shape, so the meaning can be diluted or distorted in later generation. The typical example is that the true nature of Sakyamuni the object of worship in Seokuram or the ideological foundations of Baekjae gilt bronze incense burner with dragon and phoenix 
decoration, and there are many hypothesis. Also there were many efforts to find out the symbolization in the Korean bell due to its exclusive and unequaled shape with any other creature in the world.

However, no hypothesis was accepted as an established theory of academia by gaining extensive agreements. I sincerely think that finding out the symbolic meaning cumulative in the shape would be the slightest reward for the artistic spirit of our ancestors who created the super-humanity formativeness[1]. To transmit and develop the superior wisdom science of temple bell which brought the harmony between human and nature is very important assignment. The sound of temple bells can't be excluded in order to know about Buddhism. We can find a bell in front of the access door for Buddhist sanctuary. The role and functionality of temple bells with the name of Buddha are the great heritage from our ancestors. So I expect that we protect those and get techniques to create more advanced bell for spreading. Temple bell is the work of art enough to make us have great pride for our nation.

I expect that we can utilize the temple bell which is known as the best Buddhist metal craft as the motif of our life and also expect the similar effect from religious custom that people believe they can be free from anguish at the time of listening to its sound in the formative expression by the symbolization of the bell.

\subsection{Method and range of study}

Temple bells in Korea have the unique style as they have a scientific name of 'Korean bell'. Especially the superiority of Silla bell holds the unique position that it is complemented from home and abroad. This study will analysis the formative features and patterns on the Silla bell through the general consideration for superior Korean bells holing the unique place at home and abroad as mentioned before and seek the direction of im- provement for design with a motif of Silla bell according to meet the present trend.

\section{GENERAL CONSIDERATION FOR TEMPLE BELLS}

\subsection{Origin of Temple bells}

Temple bells are used for announcing the present time, gathering people around, or performing a ceremony in temples. Also temple bells are the fruit of strong absolute authority country as well as the symbol of Buddhism. They made the bells to spread Buddha's truth and mercy to everywhere in the world and contained contributions and feats of recordable King to spread overall country and make it as the way of protecting country, and people prayed their wishes by making bells and donating it to Buddha. Eventually, the sound of the bells is the religious tool which can issue the disposition of providence to the world and report the people's wishes to god.

To inbreathe idea of defending the country with Buddha's mercy(The bell of Yeonbok temple), to attempt to defend the country by containing good deeds of King in a bell(The bell of SeongDeok the Great), and to make a wish to Buddha by making a bell are the meanings of temple bells[2].

Every temple mounted a temple bell or a large drum on a bell tower or drum tower and ring or beat either of them after the mounting of a wooden drum and cloud-shaped metal plate every morning and evening, and these four representative Buddhist instruments are called as Buddhist objects. Also drum-shaped bell, which is rung for announcement of Buddhist ceremony or meal time in Buddhist sanctuary or in dining room, is also one of well-known Buddhist instruments. Among the instruments, temple bell and drum-shaped bell are not only the Buddhist instruments but also the Buddhist tools for ceremonies, and they are the oldest tool since they has invented and used form Unified Shinra Age[3]. 
The opinion about the time for origin of temple bells comparing with the information representing the sizes of the objects and production time of Chinese bronze tools are estimated as the Bronze Age. Also the general opinions about the formative origin are roughly separated for two branches. One hypothesis is that the formative origin occurred emulating the Jong among Bak, Jeong, Jong, Joong which are included in utensils used for ancestral rites since Yin(殷) Dynasty in China. If we find more in this way, there are Jong, Jing, Jeong, La, Tangla, Geumla, Guemgo, and lyeong which have a name regarding the origin of the bells. Another opinion is that the form mixed with ancient Chinese Jong or Tak and developed to become the shape of the bell in the Buddhist temple in the Far East. The temple bells are considered as those small metal instruments with hoarse sound are greatly changed. The temple bell is also called as Kyeong jong, Dang jong, or Jojong[2,4].

The fact that it was made in early period clearly shows the simple wrought iron casting method by king Myeongjong oldest Chinese temple bell made by King Myeong throws a sidelight on the hypothesis[1].

\subsubsection{History of Korean bell}

Ringing the bell! The moment of striking the body of the bell, the metallic sound occurred by strong vibration, the rough breathing spreading to every which way, the sound of repentance softly melting the deep anguish, the eco of a secret rule realizing all things with after-sound, these are the original shape of the sound of Korean bell recognized in the world. However, more deep stage than the sound is on the shape of a secret rule. It has to be more impressive as there is no more unique shape than Korean bell across the ages and in all countries of the world. For this reason it was come into the spotlight from domestic and overseas scholars in ancient art from early 20th century and was reformed by worldwide scientific name of
'KoreanBell'.

The time that the superiority of Korean bell became known to abroad casts back to more than 1000years ago. Today there are more Shilla and Koryo bell transmitted in Japan. Many Korean bell had to be across over southern sea by Japanese people who were impressed with the beautiful pattern and deep sound. After 1000years later, now the eco of Korean bell is vibrated here and there in Japan with deep sorrow of homesickness[1].

The initial example of Korean bell can be found in the following two articles on "The heritage of the Three States"

In 6th year of Tianjia, an envoy, Yusa and a monk, Myeongkwan visited Korea from Jin Dynasty with the order of the emperor. Temples were spread like starts and towers were stood in a row like wild geese. When we stood the Buddhist sanctuary and hung the Buddhist temple bell, Yongsangseokdo became the field of good fortune and Mahayana and Hinayana became auspicious purple clouds over decline of a nation.

We established a temple for two systems sake and named a 'Daetong temple'. It is enough to be surprised by taking a life lightly according to jus tice, and flowers and white milk are calmer. After a while, the body was dead, and gentle sound of a bell rings in Dijing[5].

The time of appearance of Korean bell is generally estimated as around the middle of 6th century. It is the analysis combining of literature materials, the time of introduction of Buddhism, and related documents. However, if the historical sources are the evidences possible to know its existence, pictures could be indirect evidences as well.

Following pictures are the one of murals in the tomb made in Goguryo Age, especially in middle of 4 th century which shows that there were bells on the Korean Peninsula in the middle of 4th century. Among the various people participating in a march, two of them are carrying the drum and 


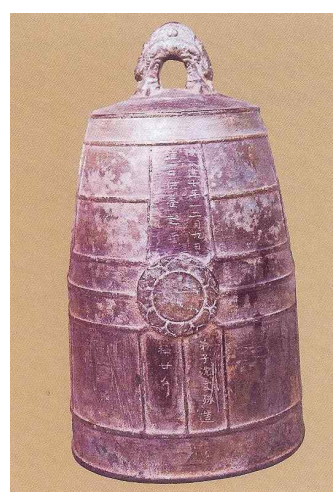

Picture 1 MyeongJong

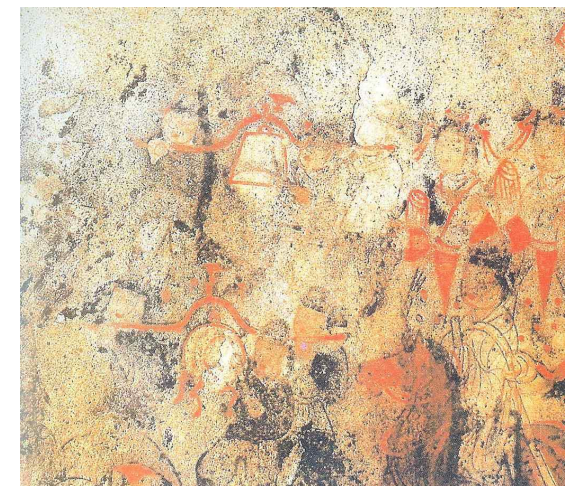

Picture 2

Murals in the tomb made in Goguryo Age

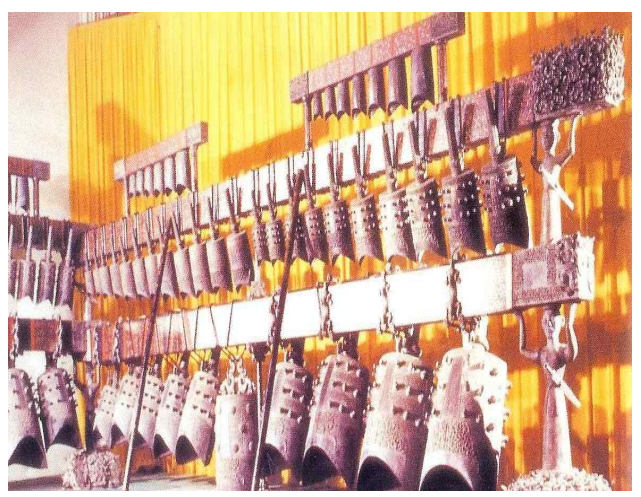

Picture 3 China is one of the high motivation akjong jeunghueul Carillon (曾侯乙 編鐘) bell respectively on their shoulder. According to this, we can estimate that horn type instruments were used in the Korean Peninsula as well as in China before the temple bell appears.

According to the record of 'The Heritage of the Three States', sometimes a story of a large bell casted with all of national power in Silla Dynasty that Buddhism was prevalent. The mighty bell of Hwangryong temple produced in 754(13th year of King KyeongDeok, Silla) has 497,581 guen(unit of weight), and the Bongdeok temple bell with 120,000geun and Sangwon temple bell made with 3,300nyang (unit of weight) of brass in $\mathrm{O}$-dae Mountain were also mighty bells[2].

The Korean bell material is bronze, iron for Chinese. By the way, Chinese and Japanese have a top decoration with two dragons, but Korean bell has only one dragon, and it has very beautiful shape(Top band, bottom band, heavenly maid, inscription) which can't be found on other bells of foreign countries.

Korean bell can be classified as Silla style, Koryo style, and Joseon style according to the age, and while the bells of Silla and Koryo age are based on pure creativity of Korean ancestors, the bells of Joseon have mixed style of Jeosun-China as they were influenced by Chinese arts. However, the style of Silla bells is recognized and known as the typical Korean bell style in these days.

\subsubsection{Name and structure of Korean bell}

'How does a Korean bell look like?' Before we introduce the features, let us see the terms appointing each part of the bell.

For the body of a bell, the top part is Jongjung or top plate, and the patterned band around the body right under the top plate is Sangdae(top band).

The decorative parts under the Sangdae is Yugwakdae or patterned frame, there are 4 set on the four sides of upper part of the body. Some people say it means four seasons, or four noble truths 'go(苦), jip(集), myeol(滅), do(道)' which are about the problems of life and their solutions. The risen bump shaped decorations are called as Jongyu, Yu, or Yudu. Regarding this, as they are the shape of lotus, some people suggested calling them as Yeonloe(蓮蕾).

The widest middle part of the body is Jongbok, and the Dangjwa (striking spot) and heavenly maid would be intagliated. The most bottom part is Jonggu or mouth of a bell, and it is Hadae or bottom band which is a patterned band around the body of the bell[2].

Korean bell is recognized as the best among Eastern countries with its beautiful appearance as well as its grand sound. The outside shape is appearance of the bell is similar with the upside-down crock. The upper part is narrow and getting wider in the middle part and getting narrow 
in the lower part again, On top of the body, there is a dragon bending its neck and opening its mouth to bite the bell. It is called as Yongnyu or top decoration, and it performs as the loop for hanging up the bell. Behind the top decoration, there is a long pipe looks like cylinder which is shown in Korean bell only, and it is called as Yongtond or Eumtong, Eumgwan(sound pipe)[3].

The traditional formative art field of three nations combining structure, sculpture, painting, and crafts developed each unique formative element based on the common denominator named Buddhism. Temple bell is not the exception in the flow. But while the common denominator is quite large between China and Japan, but Korean bell has too many creative elements. The Yongnu(loop part) is the most significant. On the other hand, the most similar part between Chinese bell and Japanese bell is also the loop; both of them use two dragons as the decoration for the loop. But Korean bell consists the loop of one dragon and one sound pipe. For the decorations on the body of a bell, Korean bell have various unique element which can't be found on the bells of Chinese and Japanese [1].

\subsubsection{The feature and its symbolic meaning of} Korean bells

The most creative formative element is sound pipe. It is called as several names of sound pipe, Sound controlling pipe, Cylinder with nodes, or Manpasikjeok and decorated as looks like up- heaved cylinder on the top plate, it is the unique formative element which is in only Korean bells, and the essential factor causing the question about the origin of Korean bell at the same time.

The feature in shape of Korean bell is getting narrowed from lower side to upper side as the shape of bronze bell in Sangwon temple looks like a shell after cutting its head, and also it is similar with upside-down crock. The part of $2 / 3$ from the bottom is the widest part, and it's getting narrowed to the bottom from the part, so it looks very stable. There is top band at the upper side of the body of Silla bell, and bottom band which as a band of patterns around the body is lower side of the body, and there are 9 nipple-shaped decorations on the upper side patterned frames. And there are 2 DangJwa(striking spot) and 2 heavenly maids (Bicheonsang) are arranged symmetrically with each other. There is a dragon shaped loop called top decoration on the top of the body of a bell. It looks like it steps on the top plate with two legs of Jongjeong that corresponds to 'Mu' of Yongjong, and Yongdu looks like it is about to bite whole bell, it can be hung up by threading the metal wire into the curved body of the dragon. Also a sound pipe is arranged on the part corresponding to 'Yong' of Yongjong next to the top decoration, the Yong of Yongjong doesn't pass through inside, so it just performs as a handle, but the sound pipe of Silla bell has unique formation passing through the inside like a pipe and perforated the inside and top plate of the body of a bell.
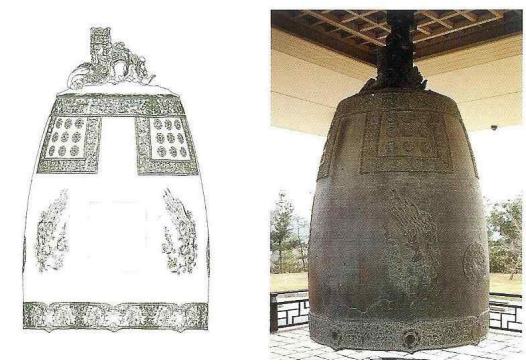

Picture 4 Bell of Seong Deok the Great

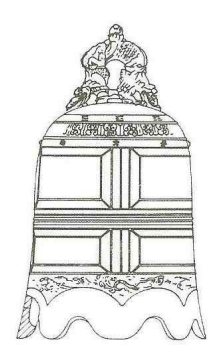

Picture 5 Bell of China Iron bell of Song
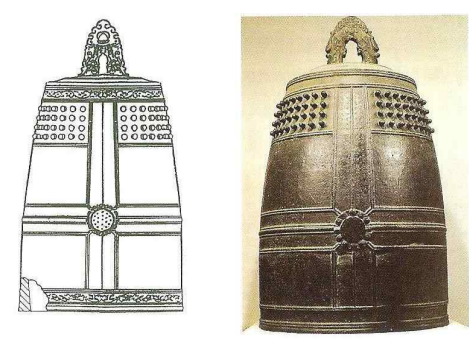

Picture 6 Bell of Japen, Cooper bell of Myosinji

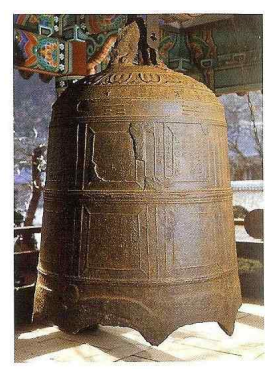


But, there is no sound pipe in Chinese or Japanese bells, and there is one-body with two-head dragon for the top decoration for Chinese and Japanese bells. They didn't arrange the heavenly maid or Buddha on the body of bells, and they fulfill all lf space of body of bells with narrow patterns and give a feeling of oppression, and that is the different point from Korean bells[2].

The most significant feature of Korean bell is sound pipe. Yongjong has similar part with it, but it is not passing through the inside of it. The sound pipe of Silla bell is passing through the inside like a pipe and perforated the inside and top plate of the body of a bell, and it is the most important point.

There is no Yongtong in Chinese or Japanese bells, and there is one-body with two-head dragon for the top decoration for Chinese and Japanese bells. They didn't arrange the heavenly maid or Buddha on the body of bells, and there are the pattern looks like it is tied with several rope in length and breadth. Or there are many nipple-shaped $\mathrm{dec}^{-}$ orations in interval plate or other empty spaces.

Japanese Hwa bell also has thin and semispherical type of top plate, and upper part and lower part of the body is almost parallel. Also the thickness of the body of Japanese bell is almost same in upper and lower parts, but Korean bell has different thickness depending on the decoration and for each part, and it is one of the features of Korean bell[4]. Like this, even it is influenced by Chinese bell in bronze production method; Korean bells have artistic and formative creativity

\subsection{Formative origin of Korean bell-Yongjong Or Manpasikjeok}

The general theories about the birth of the sound pipe of Silla bell estimated so far are roughly separated into two theories. So-called an imitation of foreign bell theory and creation of Silla theory. Former one is that the Korean bell imitated Yongjong which is one of Chinese horn type instruments, and creation theor, and later one includes symbolic theory of Manpasikjeok and origin of pole theory. The most popular two theories are Yongjong imitation theory and symbolic theory of Manpasikjeok[1].

The reason that the formation of Korean bell is based on Yongjong it there are several similarities in their appearance.

2.2.1 The core of the Yongjong imitation theory

Yongjong is one of horn type instruments appeared in Seoju Age(AC 1111 770) in ancient China and consciously was popular until Han Dynasty via the warring states period(770 259). After the Cultural Revolution, it is generally found from the tombs of advanced era, and it was hardly found for Jin Dynasty but found here and there of heritages of the next era[6].

The part of 'Yong' corresponds to the top decoration of the bell, and 'Gan' is developed and changed to 'Yongdu'. Also 'Mae' expressing 36 of bumps around ' $\mathrm{Yu}$ ' corresponding to the body of

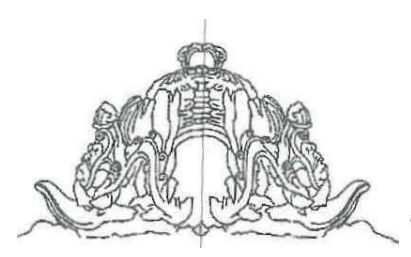

Picture 7 Bell of SeongDeok the Great's Yongnu

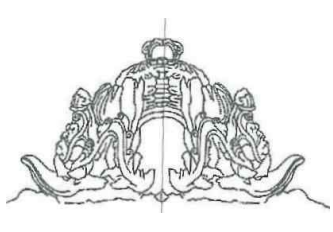

Picture 8 Yongnu of China bell

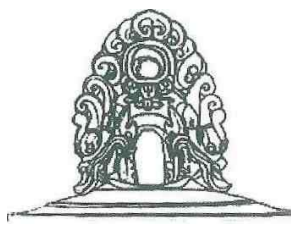

Picture 9 Yongnu of Japan bell

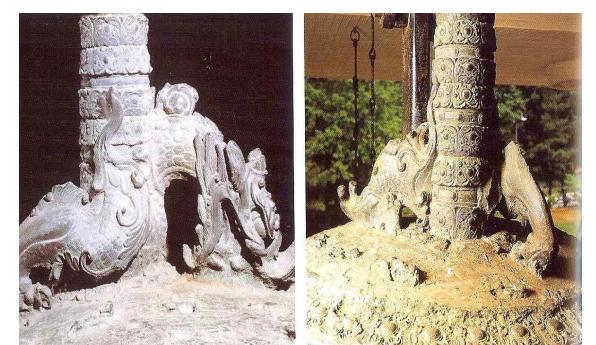

Picture 10 Bell of SeongDeok the Great's Yongnu and sound pipe 


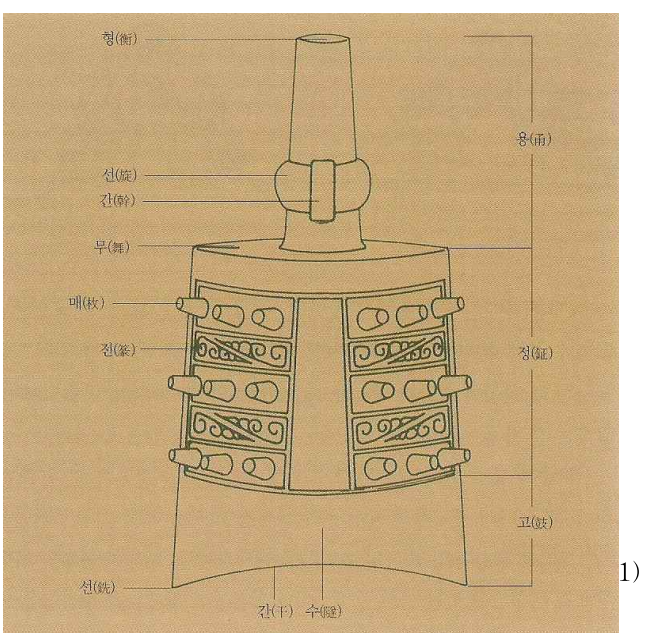

Picture 11 Parts of Yongjong

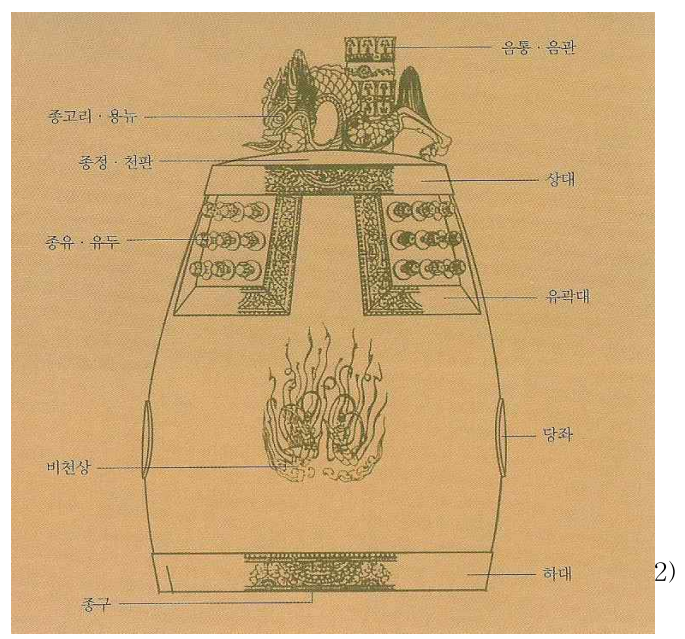

Picture 12 Parts of KoreanBell

a bell corresponds to the nipple shaped decoration on the bell, and 'Su' corresponds to striking spots. Having various features of Yongjong is one of characteristic of Korean bells[4].

2.2.2 The core of the symbolic theory of Manpasikjeok

'The symbolic theory of Manpasikjeok' suggested by Dr. Hwang Soo-young in early 1980 is a theory insists that the identity of a sound pipe of Silla bell according to the symbolization. After the death of King Moonmoo who achieved the unification of three nations, the funeral was processed in Buddhist ceremony according to his will. Then he was buried in Daeseoksang of Donghaegu, and it is Daewang tumulus. So-called the best three heritages in Donghae-gu of Gameun temple established with a wish to repulse the Japanese army, Igyeondae established by his son, King shinmoon and Daewang tumulus was completed. The large scaled royal projects could be possible by supporting of Manpasikjeok' tale, the story is like following.

According to the fortune-telling of Ilgwan, "the late king became a sea dragon and defends the

1) 음통. 음관. 종고리. 용뉴. 종정 천판. 상대. 종유 유두(영 뢰). 유곽대. 비천상. 당좌. 하대. 종구

2) 용-형. 선. 간. 무. 정-매. 전. 고-간. 수

country, and also General Kim Yu-shin came down to the world as one of Trāyastrimśa and became a great god(Syncopation). After came back and made a pipe with the bamboo tree and store it in the Cheonjon storage in Walseong, whenever playing the pipe, enemies ran away, recover from ills, rain falls down for drought, winds stop, and waves becomes calm, so people named the pipe 'Manpasikjeok' and designated it as a national treasure[5].

If a sound pipe of a bell is described as Manpasikjeok, it should have bamboo shape. As the material of Manpasikjeok is bamboo, and the sound pipe should be also circled and empty with nodes. If it is correct that a sound pipe of Korean bell described the bamboo tree as a motif, the symbolic theory of Manpasikjeok would acquire many agreements.

Fortunately, two bells with such a formation were found. The first one is the bell of early Koryo possessed in Samsun temple in Jinju city. It is relatively small bell with only $646 \mathrm{~mm}$ of height, and its top decoration is consisted of one dragon holding a cintamani in its mouth and big sound pipe. But the pipe consisted of total three nodes looks like real bamboo. The sound pipe of the bell which shows the shape of bamboo too clear to let people make a sigh is important circumstantial evidence supporting the symbolic theory of Manpasikjeok[1]. 
Another one also described bamboo tree as it looks. It is the bell of middle of Joseon showing certain year of casting and possessed in Hwaumtemple in Gurye, Jeonnam, and its name is Yumasamyeong bronze bell(Kanghui 61th, 1722). The sound pipe which started to disappear from early Joseon exists at the top decoration of the bell like a dragon twisted around the bamboo tree with its body. It looks like a bamboo tree with three nodes is embedded on the top plate. Even a mark of branch was clearly checked on the pipe[1]. The symbolization between temple bell and Manpasikjeok is very similar so the theory is very persuasive. The sound is the mean transmitted after going up the sky, and its function can be symbolized.

\subsubsection{Background set-up named 'Manpa'(Ten thousand waves)}

Another example supporting the symbolic theory of Manpasikjeok is found. It means a 'wave'.

Like the story of the tale, if the moment that a dragon flies up onto the surface of the sea carrying a bamboo tree on its back is described, the top plate of the bell means the surface of the sea. Rising wave on the surface of the sea is very natural phenomenon at the time, and the example of heritage describing detailed situation was confirmed[1].

'Manpa(Ten thousand waves)' is a word symbolically comparing to many difficulties of the troubled times. In order to overcome such situations, a pipe was created as the treasure which can make 'Manpa' calm and was named 'Manpasikjeok'. Thus, the pattern of waves on the top plate is a realistic description of the moment that a dragon flies up onto the surface of the sea and also a figurative sculpture expressing the national crisis metaphorically. It should be called as a brilliant and creative artistic idea of an ancestor who considered the symbolization of Manpasikjeok and created Silla bell.

Such a shape of Manpa is the essential and circumstantial evidence which let us check that the sound pipe of Korean bell is unique sculpture of Silla based on 'the tale of Manpasikjeok' as well as the bamboo shaped sound pipe previously[6].

We had to add 'dragon's 'at the beginning of $\mathrm{ev}^{-}$ ery words related to the king, and it because they wanted to compare the unlimited and wonderful harmonizing ability to the power of the king. At that time, the recognition of 'Dragon=King=God' came into existence and developed to the idea of defending country to create 'Defending dragon' [8].

Dragon means the King. Especially the dragon of Silla Age means a dragon defending the law and country. So a dragon was used to pray for endless royal authority and to defense the country, and we can understand the formula that the Kind is equal with defending dragon from the famous tale of King Moonmoo who accomplished five--story pagoda of Hwangryong temple and the unification of three nations that he said he will be the dragon and defend the country.

The tale of 'Manpasikjeok' is also the climax of

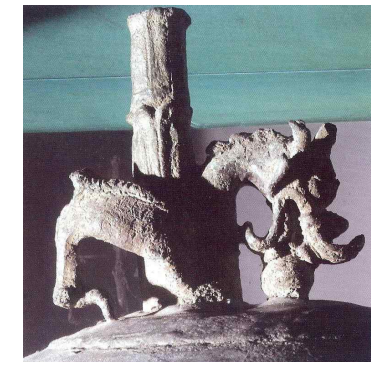

Picture 13 Cooperbell of Koryo

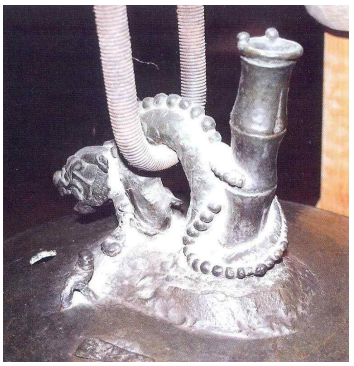

Picture 14 Yumasa bell

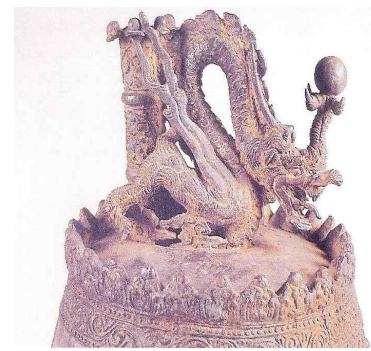

Picture 15 Cooperbell of Koryo(Late 13th century)

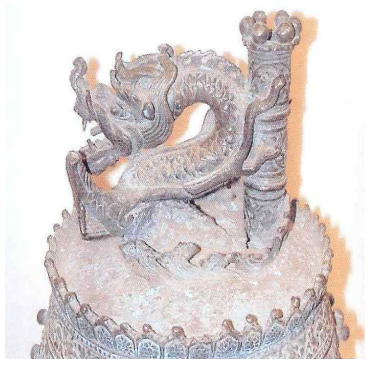

Picture 16 Cooperbell of Koryo(13th century) 
a historical drama led by defending dragon symbolizing the King of Silla. The establishment time of the 'Manpasikjeok' tale was right after the unification of three nations by Silla. At that time, people of baekje and Goguryeo could not adapt to the new unified dynasty and took defensive gestures. The situation of Silla was very corrupt by interference from Dang nation and often invasion by Japan. They need some dramatic event for $\mathrm{de}^{-}$ fensive country in order to solve the crisis. They need to fine point of mental agreement which can combine divided Silla people in early unification. The tale of 'Manpasikjeok' was formed in order to overcome the crisis situation. The tale can be more easily understand if we think about the words of German philosopher, 'Hazel', that "the aspect of artworks in an age is based on the ideas of the age"[1].

\subsection{Ringing Effect}

As we see through the example of Shilla bell, Korean bells have very unique shape and design differently from others of Chinese or Japanese. Especially the grand and long after-sound(resonance) is the best among the Eastern countries.

We can find the factor of the grand sound and long resonance from the shape of a bell. The appearance of the bell is similar with the upsidedown crock. The upper part is narrow and getting wider in the middle part and getting narrow in the lower part again, and the shape was made by consideration that the resonance can't be gone out of a bell with the narrow lower part. Also generally Korean bells are hung up on the low height from the ground. When we strike a bell, the sound occurs by pulsatile phenomenon through the resonance inside of a bell, and this sound goes out through the mouth of a bell. Therefore, the narrowed mouth of a bell holds the sound not to be gone out easily. Especially in some cases, there are holed on the ground under the bells or big crocks are buried under the bells, and those reflect the resonance going out from the bell into the bell again to hold it for longer time[3]. The scientific component and resonance well shows the scientific wisdom of Korean bells. Comparing with that Japanese people hang a bell in high height from ground to make sounds spread to far distance, but the after-sound is not very long, Korean bells are hung up on low height from ground for scientific acoustic effect from the first time.

Also there is a sound pipe raised on the back of the dragon's neck of top decoration consisting of one dragon. It is empty inside, and its lower part has a hole to pass through the inside of the body of a bell.

Therefore, it is estimated that the sound pipe performed as the sound controlling instrument related to the resonance of a bell. An opinion was suggested that the sound pipe has two functions that rapidly filter out the strong vibration to re $^{-}$ move shock from striking and spread some parts of sound into the air. So if a bell doesn't have the sound pipe absorbing shocks, the shock stays longer on the body of a bell and gives more damage to a bell, but the sound pipe keep the stable sound with low frequency for a long time and remove useless high frequency right away with funnel-shaped entry. However, about the role of the sound pipe and the aspects of resonance, we couldn't prove specific correlation about the effect from the acoustic test for The Bell of SeongDeok the Great[3].

However, it might be true that the sound pipe of Korean bell have close connection with the sound. Because the inside of the sound pipe is empty for all Koryo bells as well as unified Silla bells, and the small hole of its lower part is connected to inside of the body. Also it needs very delicate casting works to make the small hole passes through inside of the body, and it is not easy to understand if they made such the useless process without any purpose. More detailed test results and studies should be followed for the sound pipe, but 
the sound pipe is the most distinctive element and a clear evident proving the scientific aspect considering the sound of a bell on purpose.

Also there are separate striking spots on both side of front and back marked with circled decoration, the spots are commonly the most popped place of the decoration in around $1 / 3$ of body of the bell. The top place near the middle of the body locating the striking spot is the thickest part of the whole body, and it was intended to delay the damage of the bell from repeated shocks by striking.

Korean bells cared with scientific principle like above could make grand sound and long after-sound unlike the bells of other countries. By the way, the reason that the sound of bells of Koryo and Joseon is not very clear is estimated that there were many changes in the form and style from the one of unified Silla[3].

Korean bell isn't well known only with its beauty of the pattern. The sound of the bells which is grand touching people's hearts, clear, and long like breathing has aesthetic value as well as the Korean bells. The sound of Chinese bell is relatively dull and noisy with not very long resonance. The Japanese bells which are similar with Chinese bells can't make the sound beautiful as much as Korean bells causing fluctuation from deep inside. The gentle sound appears in each famous sightseeing spot.

\subsubsection{Vibration and sound}

Basically the sound of a bell caused by three types of vibration according to radiation, circumferential direction, and elasticity of a body of a bell. The biggest amplitude of vibration occurs from radial direction and the smallest one occurs from longitudinal direction. Also the amplitude according to a location of the body is reduced in order of lower, middle, and upper body. Therefore, the sound of a bell is getting louder as the striking spot is getting higher and it is getting quieter as the striking spot is getting lower[1].
Generally, the tone of a bell is a complex tone consisted of many partial tones occurs at the time of striking. The sound of a bell is separated into three parts according to the time from striking.

First part is the 'knock sound' sounding for a second after striking and including many partial tones, and the tone is related to an intensity of partial tones and the arrangement of the number of vibrations.

Second part is the 'long-distance sound' sounding to long distance, and it has relatively higher sound.

Third part is the 'pulsatile phenomenon' lasting over 1 minute, and it has a feature of very correct exponential reduction and accent. The proper number of the phenomenon is considered as 1 time for $1 \sim 3$ seconds. About 6 times of phenomenon for 1 second provide good sound to listen, but it would provide displeasure if it's over 30 40 times[2].

Likewise, the each sound from three intervals of time defines the feature of the sound of a bell.

In conclusion, the superior sound of a bell needs to have following four conditions. First, the 'knock sound' should give solemn feeling without any noise. Second, the 'long distance sound' should be high and clear for 5 10 second. Third, the after-sound should be clear and long. Commonly the after-sound of mighty bells should be lasted over 2 minutes to be recognized as qualified sound. Fourth, the pulsatile phenomenon should be clear. Excellent phenomenon is repeating to completely disappear and appear to make clear accent of $\mathrm{vi}^{-}$ bration[1].

When two sounds with different number of vibrations are overlapped, they interfere in each other and repeat strong and weak accent regularly, and the phenomenon is called as 'pulsatile phenomenon.' It is named as it has a similar pattern with regularly beating pulse. The pulsatile phenomenon seems to be removed but appears to breathe right away. This is the feature of beautiful sound of the Korean bells which can't be even chased by neigh- 
borhood countries[1].

\subsubsection{Scientific characteristics of Korean bells}

Seeing the Shilla bell which has the typical style of Korean bells, the loop of the bell is made with one dragon head decoration and a top decoration with two legs, and there is a sound pipe passes through inside of the bell in the next to the loop. There are top band and bottom band intagliated with arabesques or patterns of bines around the upper and lower in the body of the bell. Under the top band, there is a patterned frames with $1 / 4$ size of the body, and there are total 9 of nipple--shaped decoration is located on the 9 flower cups in three rows and three lines. Also there is a heavenly maid playing music intagliated between patterned frames and a lotus patterned hitting spot for the hammer on the opposite side of the frames. Also there are inscriptions intagliated on several spots on the body.

These intagliated patterns have a decorative effect and make composite tone by various sounds with different frequency from the different thick ${ }^{-}$ nesses and masses. That is, Korean bells, especially Silla bells were based on a scientific design with delicate care for the size and arrangement of the pattern according to acoustic principles[7].

The creative thing that Korea bells only have is the vibration pipe right under the sound pipe and bell mouth in upper body of the bell. Sound pipe is also called as tone sound container or soundcontrolling pipe, and it is estimated it has an acous ${ }^{-}$ tic function making sound quality and tone better. In the inside of the sound pipe, it has narrow entry, and it is not the straight line as it looks like from outside. The vibration from the entry and acoustic wave from the sound pipe interact on each other to make the echo sound. According to the explanation of Yum Young-ha, the sound pipe performs as an acoustic filter that removes the shock from internal vibration making noise by clash and discharge the part of the vibration into the air for filtering the noise. In other words, it helps the bells to make a clear and good sound without any noise.

The vibration and sound are on the vibration and vibration pipe of the body and their source are in the body of the bell. Vibration pipe make long after-sound at the time of hitting the bell by vibrational resonance of it. If he number of vibrations is same with dominant frequency (It is $64 \mathrm{~Hz}$ for the bell of the Great king SeongDeok ) arousing pulsatile phenomenon, the sound and vibration pipe cause resonance to make a good echo, that is, a long after-sound[7].

Eventually, Korean bells was designed considering the way to spread on sky, ground, and people as well as the sound from the body through the sound pipe on upper side and vibration pipe on lower side of the bells.

Korean nationality already made the unique and

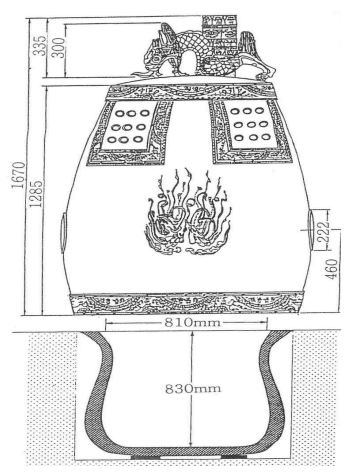

Picture 17 Sangwon temple bell

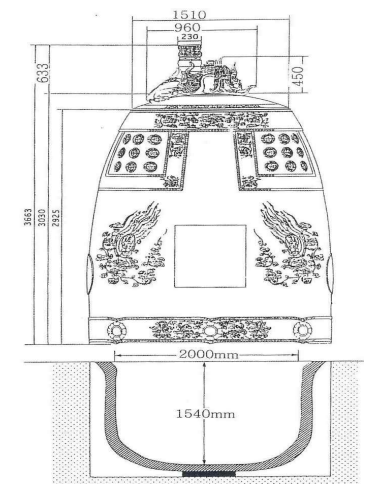

Picture 18 Bell of SeongDeok the Great

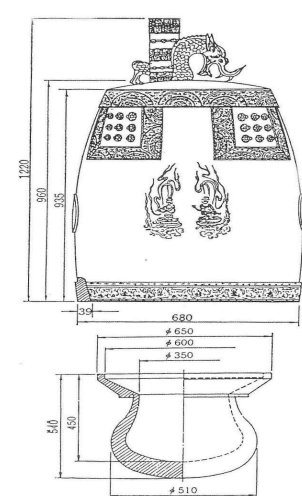

Picture 19 Sunrimwon temple bell 
only bells in unified Shilla age such as The Bell of SeongDeok the Great by optimizing excellent scientific wisdom and creativity for the design of acoustics and vibrations called in the advanced modern science and the way to striking a bell[7].

We can peek at the brilliant scientific characteristic and national wisdom of ancestors who made acoustic effects according to the thickness of the material and also the formative meanings of every single pattern.

\subsection{Silla Bell-Creativity built up the model of Korean bells}

Korean bell can be classified as Silla style, Koryo style, and Joseon style according to the age, and while the bells of Silla and Koryo age are based on pure creativity of Korean ancestors, the bells of Joseon have mixed style of Jeosun-China as they were influenced by Chinese arts. However, the style of Silla bells is recognized and known as the typical Korean bell style in these days.

\subsubsection{Founding 13th year Myeongdong bell / Sangwon Temple}

There is no temple bell left from the period of the Three States. The Founding 13th Myeongdong bell is the oldest Korean bell casted in unified Silla in Sangwon temple in $\mathrm{O}-$ dae Mountain in Gangwon-do.

It is a large sized bell over 5 cheok(unit of length), and it is a masterpiece representative Korean bells in every way of the pattern, top deco-

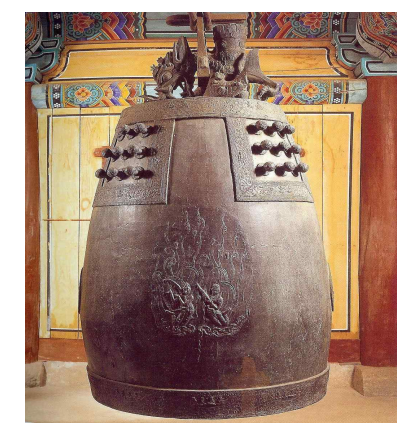

Picture 20. Sangwon Temple bell ration, the status of casting, casting method, and the sound of bell. However, ironically, this is the oldest Silla bell left. No master who was born with outstanding creativity and a sense of formation can make a perfect bell like this. It can be called as the unprecedented masterpiece, and this was the reason that the history of Korean bell was sunken into the tunnel of parallelogram.

With the top decoration as the center, there are total 70 intagliated letters of inscription on the top board. Excepting few letters illegible, we can understand the year of casting and the occupations of monks and supervisor, and officers who participated in the casting project[1].

\subsubsection{The bell of SeongDeok the Great / National} Kyeongju Museum

The bell of SeongDeok the Great was casted and donated to BongDeok temple according to the order from the King for the country's sake. King KyeongDeok started the casting project after gathering 120,000 geun of bronze in order to pray for the repose of the late king's soul with love for his father, but he had died before the bell was completed. So his son, King HyeGong took over the project and completed the project in 771 . The bell was donated to BongDeok temple, the Buddhist sanctuary of SeongDeok the Great. With this reason, it is also called as The Bell of BonkDeok Temple and more famous as with the name of 'Emilre Bell'. After then, it transferred to National Kyeongju Museum in 1975 via Youngmyo temple,

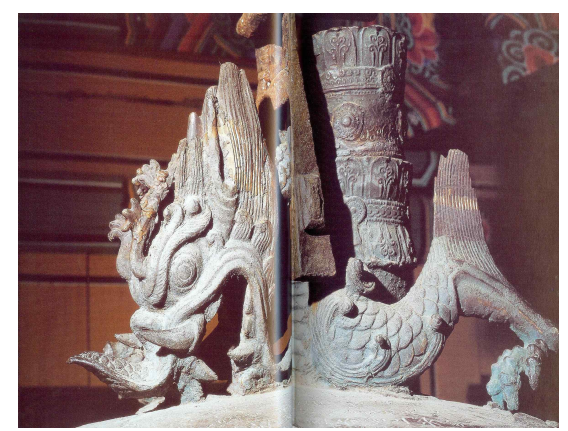

Picture 21. Yongnu of Sangwon Temple bell 


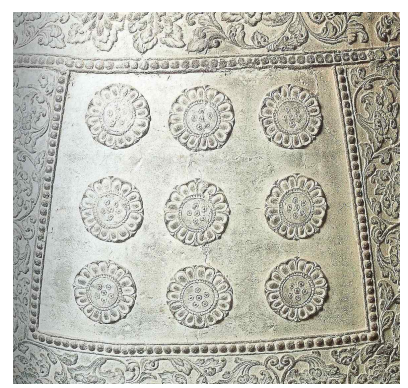

Picture 22 The bell of SeongDeok the Great's Yugwakdae

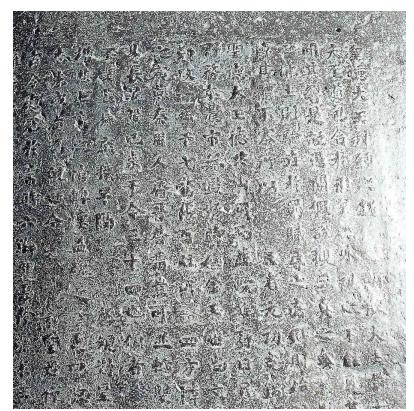

Picture 25 The bell of SeongDeok the Great's part of posy

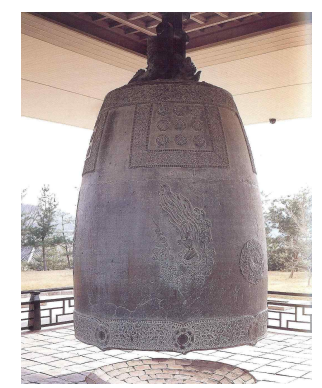

Picture 23 The bell of SeongDeok the Great

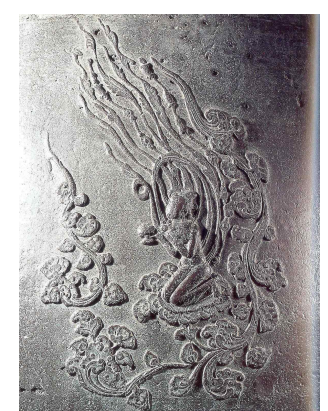

Picture 26 The bell of SeongDeok the Great's Bicheonsang

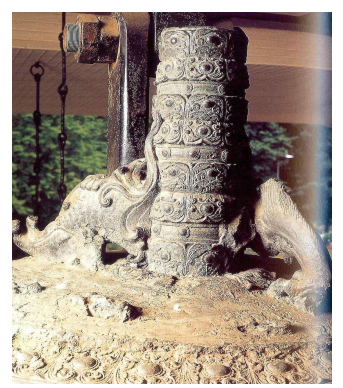

Picture 24 The bell of SeongDeok the Great's sound pipe

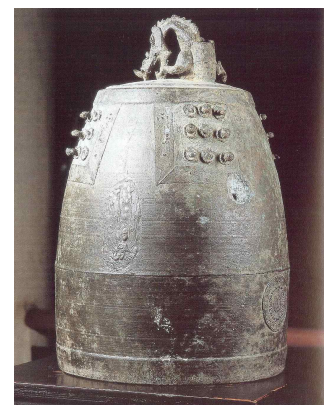

Picture 27 Korea's Treasure No. 1167, Shilla bronze bell
Nammoon of Eupseong in Kyeongju, and amuseum in Dongbu-do[1]

\subsubsection{Silla bronze bell in National Cheongju Museum}

Silla bronze bell in Cheongju museum designated as Korea's Treasure No. 1167 is one of three intact Silla bells transmitting in Korea. It show almost perfect status excepting its top decoration, it is a pity that it doesn't have any inscription to show its casted year.

This bell was found under construction for a newly built house in Wooncheon-dong, Cheongjucity, Chungcheongbuk-do in 1970 and transferred to Gongju Museum right away and return to the place where it was found after Cheonju museum was opened. At that time, a safe, a bowl of incense, a gilt bronze statue of the Buddha was founded with the bell, and the name of the temple, 'Gu(Hoe)Yangshi' could be read from the inscription on the safe. However, the most opinions insist that the temple is not the original location for the found heritages as it was established much later than the time of production of the bell.

In accordance with Mounument of Silla found around the location in 1982, it is more likely to be the temple site of later Silla Age. Also according to discovery of a large temple site in 1984, it was estimated that there was a temple site which was highly prospered and connected to near Ancient Baekje-era Tombs and the site of Heungdeok temple[1].

\section{AESTHETIC SENSE ON TEMPLE BELLS}

Someone says the beauty of Korean work of art is on 'line' and 'shape', and someone says the most clearest feature of Korean arts is great sense about 'shape' and 'balance'. Also someone evaluates that Korean arts are 'natural beauty' or 'the art of nature', and those mentions are all the indispensable admirations and also correct views for Korean arts. 
Korean bell can be called as assembly consisted of metal crafts from top decoration to the body of a bell. Diversity of its pattern, rhythmic texture and diversity of sculptures of a flying fairy, Buddhist saint, and Buddha, splendor of sculptures and selection of locations, and casting and alloying techniques for temple bells have been changed according to each age.

Also the features of each age and statement of the times are beautifully and smoothly displayed and expressed on the dimension of temple bells. This is the superiority and feature of Korean bells and also the fruit of 'beauty', 'line', and 'shape' of Korean ancient arts[4].

Among temple bells with these features, the standards representing basic form and style of Korean bells are temple bells of Silla Age. In other words, Silla bell is the standard of Korean bell style.

Among the Silla bells, The Bell of SeongDeok the Great is only one bell which deserved nationally representing Korean style bronze bells, and there is Nama, Park Han-mi among people who casted this famous bell. According to the names on the bell, casting great mater Daenama(大奈麻) is written with somebody(某), and next edge Daesa(大舍) is written with somebody(某), so total four people made this bell together, but the letters were worn out and other three people's name has been erased but only one people, Park Han-mi. Regarding the order of ranks in the factory, Daenama is 10th among total 17 ranks, Nama is 11th, and Daesa, Hansa is 12 th, so we can estimate the social position of Park Han-mi. He was a Nama but also a casting mater, so we can only guess tha the was one of maters of casting lived in the time of reign by the King Hyegong according to his last work without any information of his world, date of birth, month, or year. However, we can understand his position as an artist by discussing about what the meaning and value The Bell of SeongDeok the Great has which is his last work[8].
The Bell of SeongDeok the Great holds the representative position as Korean bell in some aspects of the invocation of the spirit, the exquisite workmanship, and the beautiful sound. As there won't be nothing like as good as the bell in the world, previously when the Dr. Kummel, from German national museum visited Korea, he transferred the word, 'the best in Joseon' of the bell with a pencil to 'the best in the world' and said, "It is should be called the world best, not only the best in Joseon. If it was in German, we would make a museum only for this." Also he explained, "With this, I can understand the highest artistic value of this bell, and its special shape of style model can be called as the creative style of Joseon as it can't be found in anywhere in the world but in Joseon, but we can't affirm it until the Chinese bells which were the leader of culture are clarified enough." With this, we can guess the outstanding creativity of Korean bell has very high artistic value[8].

\section{CONCLUSION}

In Hwangryonggol of Seorabeol in Silla, there was a village named 'Jeolgol village' which has 99 temples as it was the city representing national $\mathrm{de}^{-}$ fense Buddhism, and there would be no doubt that Buddhist arts was highly developed in the city and age. The Silla Age was the golden age of Buddhist arts. The formative aesthetic of Temple bell as a Buddhist instrument among the crafts used for Buddhist ceremony is the pride of Korean nationality. We can guess the sound of bell spreading from each temple to the Buddha land of Silla where the topography of Seorabeol is bell-shipped basin at the time of ceremony is mysterious music which is too beautiful for words and the sound leading us to heaven, that is, the music of realization. The biggest reason that Korean bell has aroused interest in from early 20th century to today was on the acoustic element as well as creative formative element. As we have seen pre- 
viously, there are some points of similarity between the Chinese and Japanese bells. However, only Koreanbell is beyond the 'the similarity of cultural heritage in same cultural sphere' according to mutual exchange and stands alone like an isolated hero.

This paper researched about general consideration of bronze bell such as the shape, use, access to the pattern and sound, pulsatile phenomenon, and Doppler Effect and the feature and formative factors of Korean bell, and it can be summarized like following.

First, it has unique and beautiful shape and clear and long after-sound. It is the reason the bell could get the scientific name of 'Korean Bell' and its superiority is well recognized in the world. The formation of the bell was completed in Silla bell.

Second, as a kind of percussions casted with metal, the bells have practical function which inform the time, but it also has symbolic meaning in design function by motif of Manpasikjeok and intension for transmitting the ability of the dragon, the mystery and the sound which are freely movable to the sky from the Sea God idea. The Buddhist sermon to Korean nationality is the sound of repentance melting anguish and also the message of the King as same as the sound and providence of God.

Third, the core of the formativeness which is only for Korean bell is 'cylindrical and knotted method'. It is called in various words such as sound container, sound pipe, sound ${ }^{-}$-controlling pipe, $\mathrm{cyl}^{-}$ inder pipe, or Manpasikjeok, but as seeing the $\mathrm{ex}^{-}$ ample of the lesson of Buddha, we could check it is Manpasikjeok that enemies leave, illness is cured, raining comes for drought, rainy season is stopped, and wave becomes calm.

Fourth, It casted the bell of SeongDeok the Great which is unique and only one in the world with bronze casting technology by optimizing with excellent scientific idea and creativity such as design, casting and heating method considering acoustics and vibrations from Unified Silla Age to modern advanced engineering. Especially, there are sound pipe on top of the bell and rumbling on the bottom of the bell in order to design the method of spreading of sound that occurs from the body of the bell to sky, ground, and people.

Like this, we could see the scientific wisdom and formative custom of Korean nationality which are made through elaborate plan and process with tools that master craftsmen who have their own method by accumulating experiences for several decades improved or created. We hope the application and commercialization of an image of the bells utilizing intellectual property of ancestors become the motif of living arts and are utilized for spreading the identity and superiority of Korean nationality. We also hope Korean scientific wisdom within the casting technology of Korean bells can be widely known and be transmitted and developed so that more beautiful sound of the bell can be rung in complex and unstable modern society, and for the last, we wish this paper can be a chance that people have understanding and new interest in Korean bell.

\section{REFERENCES}

[1] Dong Hai Kwak, the Temple Bell, Hangilart, Paju, Korea, 2006.

[2] Seong Gwan Ko, The Iron Craftsmen, Pia Publishing, Paju, Korea, 2006.

[3] Eung Cheo Choin and Yeon Su Kim, The Metal Crafts, Book Publishing Sol, Seoul, Korea, 2004.

[4] Ho Gwan Lee and Jae Sik Son, the Temple Bell, Daewonsa, Seoul, Korea, 1989.

[5] Ilyeon and Won Jung Kim, The Heritage of the Three States, Minumsa, Seoul, Korea, 2008.

[6] Won Ryong Kim, The Korea Art History, Beommunsa, Seoul, Korea, 1968.

[7] Dong Chan Jeong, Yong Hyeon Yun, and Dae 
Sik Yun, the Science and Technology Research Brethren, National Science Museum, Daejeon, Korea, 2004.

[8] Yu Seop Ko, The Korean Art History, the Second Volume, an Itemized Discussion, Yeolhwadang, Paju, Korea, 2007.

[9] Dong Hai Kwak, A Study on the Formative Style of the Korean, Chinese and Japanese Bell, PhD Thesis of Dongguk University, 1999.

[10] The Academy of Korean Studies, The Korea National Culture Encyclopedia, SungNam, Korea, 1994.

[11] Su Young Hwang, "Silla Bell and Legend, Man Pa Sik Jeack(萬波息笛) (a flute that put ten thousand waves into rest)", Silla Culture, Vol 1, pp. 7-11, 1984.

[12] Dong Hai Kwak, A Study on the Dragon Hangers of Korean Hanging-bell in the Shilla Dynasty, Master's Thesis of Dongguk University, 1993.

[13] Kim, Sun-Sim, A Study on Unified Silla Bell Formative Characteristics, Master's Thesis of Han-Nam University, 2001.

[14] Eun Jung So, A Study on Art Jewelry Expressing Reflection Images of Korean Bells, Master's Thesis of Won Kwang University, 1999.

[15] Rhee Boon, A Study on the Dragon Hangers of Buddist Temple Bells in the Shilla Dynasty, Master's Thesis of Dong Guk University , 1981.

[16] Pae Gang Hwang, Myths of Korea Research, Saemunsa, Seoul, Korea, 2006.

[17] Jae-hyuck Lee and Cheeyong Kim, "A Study on Arts and Crafts ideas with Works of William Morris," Journal of Korea Multimedia Society, Vol. 16, No. 9, pp1119-1133, 2013

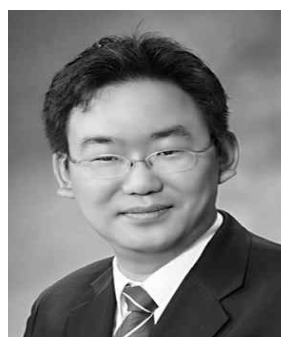

LEE Jaehyuck

LEE Jaehyuck acquired a bachelor's degree in Physics from Soonchunhyang University, a master's degree in Physical Education from the graduate school of education Kyunghee University, and He study Formative design in the graduate school of education Kyunghee University.

Now, he work in administration office of Gyeongju Middle and High Schoool from 2008.

He did not attend a lot of exhibition but He has worked steadily. And he interest in Formative Design, Ceramic arts and Educations

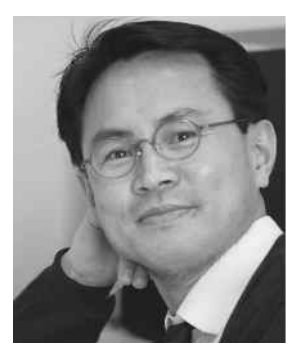

\section{KIM Cheeyong}

Professor KIM Cheeyong acquired a bachelor's degree in Physics and a master's degree in Computational Physics from Inje University. He worked as a researcher at the Institute of $\mathrm{Com}^{-}$ puter Design Education of Inje University from 1991 to 1999, full time lecturer of Department of Information and Communications at Busan Info-Tech College from 2000 to 2002, assistant professor of Department of Digital design at Dongseo University from 2003 to 2005, visiting professor at Oxford University in 2007, and visiting professor of the Digital Clothing Center at Seoul National University in 2012. Currently, he is an associate professor of Department of Visual Information Engineering at Dong-Eui University. Prof. Kim held private $\mathrm{ex}^{-}$ hibitions four times both in Seoul and China and joined over 200 international group exhibitions. With his deep interest in 3D Animation, Fractal \& Chaos Design, Computational Simulation, and 3D virtual fashion fitting, Kim passionately researches and gives presentations on the convergence of film and engineering. 